\title{
Multitemporal spectral mixture analysis for Amazonian land-cover change detection
}

\author{
Dengsheng Lu, Mateus Batistella, and Emilio Moran
}

\begin{abstract}
The complex landscape and environmental conditions in the moist tropical region often result in poor land-cover change detection accuracy using traditional change detection methods. This paper explores linear spectral mixture analysis (LSMA) of multitemporal thematic mapper (TM) images to detect land-cover change in Rondônia, Brazilian Amazon basin. Three image endmembers (shade, green vegetation, and soil) were developed based on a combination of field data and image scatterplots. An unconstrained least-squares solution was used to unmix the multitemporal TM images into three fractions. Then, fraction image differencing results were used to analyze land-cover change/non-change detection. The detailed "from-to" change detection was implemented using a pixel-by-pixel comparison of classified images, which were developed using a decision tree classifier on the multitemporal fraction images. This study indicates that LSMA is a powerful image processing tool for land-cover classification and change detection. The multitemporal fraction images can be effectively used for land-cover change detection. The stable and reliable multitemporal fraction images developed using LSMA make the change detection possible without the use of training sample datasets for historical remotely sensed data. This characteristic is particularly valuable for the land-cover change detection in the Amazon basin.
\end{abstract}

Résumé. Le paysage complexe et les conditions environnementales caractéristiques de cette région humide tropicale entraînent souvent une précision faible dans le contexte de la détection des changements dans le couvert basée sur l'utilisation des méthodes traditionnelles de détection du changement. Cet article explore l'analyse spectrale mixte (LSMA) appliquée aux images multitemporelles de «thematic mapper» (TM) pour la détection des changements dans le couvert dans la région de Rondônia, dans le bassin du fleuve Amazone. Trois composantes spectrales pures d'images (ombre, végétation verte et sol) ont été développées basé sur une combinaison de graphiques de corrélation dérivés des données de terrain et des images. Une solution non contrainte par moindres carrés a été utilisée pour démixer les images multitemporelles TM en trois fractions différentes. Ensuite, les résultats de la différenciation des fractions d'images ont été utilisés pour la détection des zones avec changement / sans changement dans le couvert. La détection en détail du changement "de / à" a été appliquée en effectuant une comparaison pixel par pixel des images classifiées, qui ont été ensuite développées à l'aide d'un classificateur basé sur un arbre de décision appliqué aux images multitemporelles des fractions. Cette étude montre que la technique LSMA est un outil de traitement d'image puissant pour la classification du couvert et la détection du changement. Les images multitemporelles des fractions peuvent être utilisées efficacement pour la détection du changement dans le couvert. Les images multitemporelles des fractions, stables et fiables, développées à l'aide de la technique LSMA rendent possible la détection du changement sans recours à l'utilisation d'ensembles de données d'entraînement dans le cas des données historiques de télédétection. Cette dernière caractéristique est particulièrement importante pour la détection du changement dans le couvert dans le bassin de l'Amazone.

[Traduit par la Rédaction]

\section{Introduction}

Change detection techniques can be roughly grouped into two categories: (1) those detecting binary change/non-change information, such as using image differencing, image ratioing, vegetation index differencing, and principal component analysis (PCA); and (2) those detecting detailed "from-to" change trajectory, such as using the post-classification comparison and hybrid change detection methods ( $\mathrm{Lu}$ et al., 2004). Previous literature has reviewed a variety of change detection techniques (Singh, 1989; Coppin and Bauer, 1996; Jensen, 1996; Yuan et al., 1998; Serpico and Bruzzone, 1999; $\mathrm{Lu}$ et al., 2004). When implementing change/non-change detection, one critical step is to select appropriate thresholds in both tails of the histogram representing the changed areas (Singh, 1989). Two methods are often used for selection of thresholds (Singh, 1989; Yool et al., 1997): (1) interactive procedure or manual trial-and-error procedure - an analyst interactively adjusts the thresholds and evaluates the resulting image until satisfied; and (2) statistical measures - selection of a suitable standard deviation from the mean. The disadvantages of the threshold technique are that $(i)$ the

Received 7 March 2003. Accepted 21 July 2003.

D. $\mathbf{L u}^{1}$. Center for the Study of Institutions, Population, and Environmental Change (CIPEC), Indiana University, 408 N Indiana Avenue, Bloomington, IN 47408, U.S.A.

M. Batistella. Anthropological Center for Training and Research on Global Environmental Change (ACT), Indiana University, Bloomington, IN 47405, U.S.A., and Brazilian Agricultural Research Corporation, Embrapa Satellite Monitoring Campinas, São Paulo, Brazil.

E. Moran. CIPEC, Indiana University, Bloomington, IN 47408, U.S.A., and ACT, Indiana University, Bloomington, IN 47405, U.S.A.

${ }^{1}$ Corresponding author (e-mail: dlu@indiana.edu). 
resulting differences may include external influences caused by atmospheric conditions, sun angles, soil moistures, and phenological differences in addition to true land-cover change; and (ii) the threshold is highly subjective and scene-dependent, depending on the analyst's familiarity with the study area and skill. When implementing detailed "from-to" change detection, the results are mainly dependent on the classification accuracy for each date being analyzed (Jensen, 1996). In other words, the classification errors from the individual-date images will affect the final change detection accuracy. The critical step is to develop an accurate classification image for each date. However, the complex landscapes and environmental conditions, particularly in the Amazon basin, often result in poor land-cover classification accuracies using conventional classifiers. Although many efforts have been made to improve land-cover classification and change detection in the Amazon basin (Mausel et al., 1993; Brondízio et al., 1994; Moran et al., 1994a; 1994b; Adams et al., 1995; Brondízio et al., 1996; Roberts et al., 1998a), acceptable accuracies are often not achieved without assistance of abundant and high quality training sample data. On the other hand, the collection of a large number of field data is, in particular, costly and impractical in the Amazon basin. Therefore, applications of historical remote sensing data for land-cover classifications are often difficult because of lack of ground truth data. This problem often induces difficulty in detecting land-cover "fromto" change. It is necessary to develop a method that does not require use of training sample data for the classifications of historical remote sensing data.

Linear spectral mixture analysis (LSMA) approach supports repeatable and accurate extraction of quantitative subpixel information (Smith et al., 1990; Roberts et al., 1998a). It is regarded as a physically based image processing tool that can be used to extract fractions representing areal proportions of the endmembers within the pixel. The LSMA approach assumes that the spectrum measured by a sensor is a linear combination of the spectra of all components within the pixel (Adams et al., 1995; Roberts et al., 1998a). Hence, using the LSMA approach can develop fractions through unmixing the multispectral image based on selected endmembers. Previous research has indicated that the LSMA approach can be used for landuse/land-cover classification (Cochrane and Souza, 1998; Ustin et al., 1999; Aguiar et al., 1999; DeFries et al., 2000; Theseira et al., 2002; Lu et al., 2003b) and change detection (Adams et al., 1995; Roberts et al., 1998a; 2002; Shimabukuro et al., 1998; Elmore et al., 2000; Rogan et al., 2002). This paper examines the potential use of LSMA for Amazonian land-cover change detection.

\section{Methods}

\section{Description of study area}

Rondônia has experienced high deforestation rates during the last two decades. For example, the deforestation rates in Rondônia range from $1.14 \%$ to $2.62 \%$ per year between 1991 and 2000, much higher than the overall deforestation rate (ranging from $0.37 \%$ to $0.80 \%$ per year) in the Brazilian Amazon basin in the same period (Instituto Nacional de Pesquisas Espaciais (INPE), 2002). Following the national strategy of regional occupation and development, colonization projects initiated by the Brazilian government in the 1970s played a major role in this process (Moran, 1981; Schmink and Wood, 1992). Most colonization projects in the state were designed to settle landless migrants. The immigrants transformed the forested landscape into a patchwork of cultivated crops, pastures, and a vast area of fallow land.

The study area is located at Machadinho d'Oeste, northeastern Rondônia (Figure 1). The size of the study area is approximately $1000 \mathrm{~km}^{2}(30 \mathrm{~km} \times 34 \mathrm{~km})$. Settlement began in the mid-1980s and major deforestation occurred in the late 1980s. The climate in this study area is classified as equatorial hot and humid with a tropical transition area. A well-defined dry season lasts from June to August, and the annual average precipitation is $2016 \mathrm{~mm}$ (Rondônia, 1998). The annual average temperature is $25.5^{\circ} \mathrm{C}$. The terrain is undulating, ranging from 100 to $450 \mathrm{~m}$ above sea level. The main tree communities are imbauba, lacre, leguminosae, mimosoideae, para-para, and urucum. Several soil types have been identified, mainly alfisols, oxisols, ultisols, alluvial soils, and other less spatially represented associations (Bognola and Soares, 1999). Settlers, rubber tappers, and loggers inhabit the area, transforming the landscape through their economic activities and use of resources (Batistella, 2001). Farming systems are mainly household-based, and little depends on group efforts. Loggers play a major role in providing access to remote areas within the settlement as they open trails through the forest to reach valuable species.

\section{Data collection and preprocessing}

Fieldwork was conducted during the dry season of 1999. The procedure used for surveying vegetation was a multilevel technique adapted from the methods used by the Center for the Study of Institutions, Population, and Environmental Change (CIPEC, 1998) at Indiana University. Preliminary image classification and band composite printouts indicated candidate areas to be surveyed, and a flight over the areas provided visual insights about the size, condition, and accessibility of each site. The surveys were carried out in areas with relatively homogeneous ecological conditions (e.g., topography, distance from water, and land use) and uniform physiognomic characteristics. After defining the area to be surveyed (plot sample), center points for three sets of nested subplots (1, 9, and $100 \mathrm{~m}^{2}$ ) were randomly marked to cover the variability within the plot sample. A detailed description of field data collection methods and the statistical description of vegetation inventory data were provided in Batistella (2001) and Lu et al. (2003a). During fieldwork, stand parameters such as total tree height and diameter at breast height in 26 plots covering secondary succession and 14 plots covering mature forest were measured. Meanwhile, more secondary succession and mature 
forest plots, and many other land-cover observations (such as degraded pastures, cultivated pastures, coffee plantations, bare lands, etc.) were identified during the fieldwork. Every plot was registered with a global positioning system (GPS) device to allow integration with other spatial data in geographic information systems (GIS) and image processing systems.

Two Landsat 5 thematic mapper (TM) images of 15 July 1994 and 18 June 1998 were acquired and used in this research. For change detection application using multitemporal remote sensing data, accurate geometric rectification and atmospheric calibration are two important aspects in image preprocessing. The 1998 TM image was first geometrically rectified into UTM projection (Universal Transverse Mercator, south 20 zone) using control points taken from topographic maps at 1:100 000 scale. Then the 1994 TM image was registered to the same coordination system as the 1998 TM image. The nearestneighbor resampling technique was used and a root mean square error of less than 0.5 pixel was obtained for both dates of TM images. Then, an improved image-based dark object subtraction (DOS) model was used to implement atmospheric correction for both TM images (Lu et al., 2002). The gain and offset for each band and sun elevation angle were obtained from the image header file. The path radiance was identified based on clear water for each band. The atmospheric transmittance value (average for each spectral band derived from radiative transfer code) for each visible and near infrared bands was derived from Chavez (1996). For middle infrared bands, the atmospheric transmittance was set to one. A detailed description about the DOS model is provided (Chavez, 1996; $\mathrm{Lu}$ et al., 2002). The surface reflectance values after calibration fall within the range between 0 and 1 . For the convenience of data analysis, the reflectance values were rescaled to the range between 0 and 100 by multiplying 100 for each pixel.

\section{Endmember selection and unmixing TM images}

A variety of endmember selection methods have been developed (Adams et al., 1993; Settle and Drake, 1993; Bateson and Curtiss, 1996; Tompkins et al., 1997; Mustard and Sunshine, 1999). For most remote sensing applications using LSMA, the image-based endmember selection method is often used because the endmembers are easily obtained and represent spectra measured at the same scale as the image data (Roberts et al., 1998a). In general, the image endmembers are developed from the extremes of the image feature space, assuming they represent the purest pixels in the images (Mustard and Sunshine, 1999). Three or four endmembers are often used (Adams et al., 1995; Roberts et al., 1998a; Lu et al., 2003b). In this study, endmembers were initially identified from the 1998 TM image based on ground truth data. The shade endmember was identified from the areas of clear and deep water and the green vegetation $(\mathrm{GV})$ endmember was selected from the areas of dense initial successional vegetation. Soil endmembers were selected from road intersections and from bare soils in agricultural lands. The reflectance features of these initially selected endmembers were compared with those endmembers

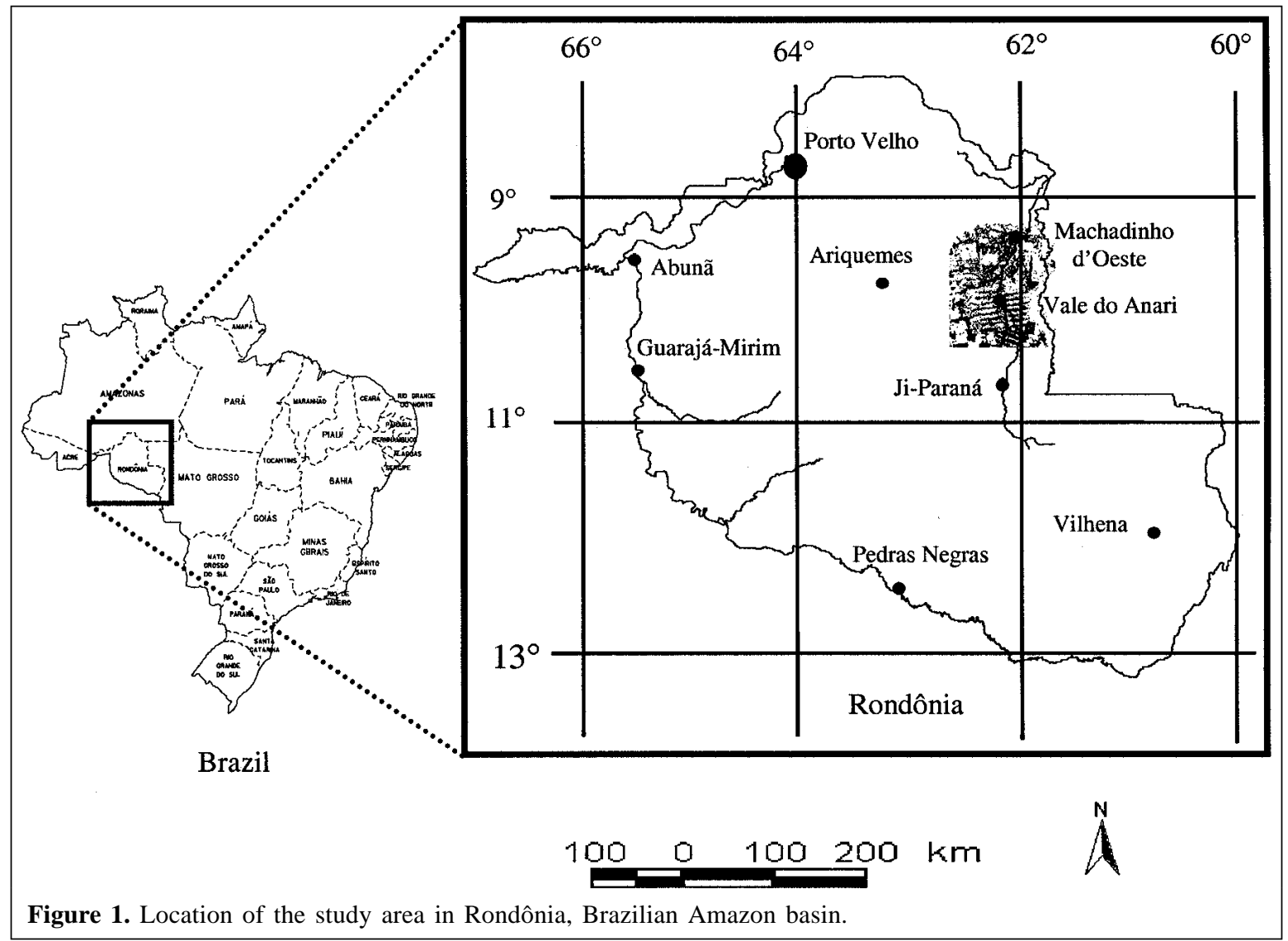


selected from the scatterplots of bands TM 3 and TM 4 (Figure 2a) and of bands TM 4 and TM 5 (Figure 2b). The endmembers whose reflectance curves were similar but located at the extreme vertices of the scatterplot were finally used. An average of 10 to 15 pixels of these vertices was calculated. Figure 3 illustrates the reflectance characteristics of the selected three endmembers. They are independent of each other. After determination of endmembers, an unconstrained least-squares solution was used to unmix the 1998 TM image into three endmember fraction images. The same method was used to unmix the 1994 TM image into shade, GV, and soil fraction images. Then the multitemporal fraction images were used to implement land-cover classification and change detection.

\section{Change detection analysis}

Different fraction images have their own characteristics in representing land-cover types, and different vegetation stand structures and land-cover types have different area proportional compositions of the endmembers. For example, vegetation and nonvegetation have significantly different soil fractions - very low soil fractions for vegetation covers and high values for nonvegetation covers except water. Thus, soil fraction differencing image from two dates can be used to detect vegetation deforestation or reforestation. In the shade and GV fractions, different vegetation types such as successional and mature forests have different fractions owing to their different vegetation stand structures. Also vegetation and nonvegetation have different shade and GV characteristics. Thus, the fraction differencing images of bi-temporal shade or GV fractions can be used to detect the changes between different vegetation types, in addition to the changes between vegetation and nonvegetation. The image differencing method of bi-temporal fractions can be expressed as follows:

$\Delta$ Shade $=$ Shade $(\mathrm{t} 1)-$ Shade $(\mathrm{t} 2)$

$\Delta \mathrm{GV}=\mathrm{GV}(\mathrm{t} 1)-\mathrm{GV}(\mathrm{t} 2)$

$\Delta$ Soil $=\operatorname{Soil}(\mathrm{t} 1)-\operatorname{Soil}(\mathrm{t} 2)$

where $\mathrm{t} 1$ and $\mathrm{t} 2$ are the prior and posterior dates for the change detection. So, the fraction differencing results can be used for land-cover change detection through the use of suitable threshold methods. In general, thresholds were determined
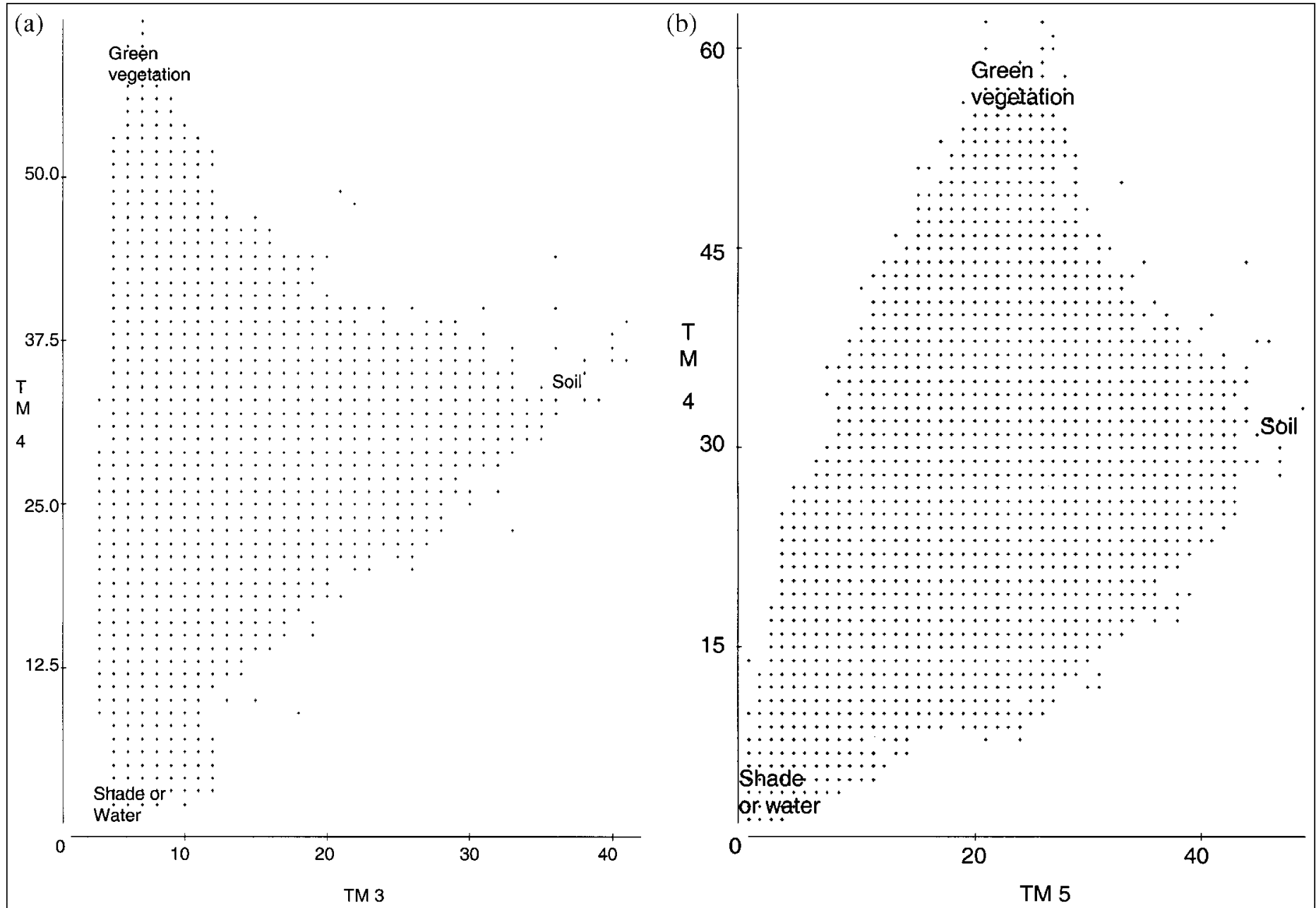

Figure 2. Scatterplots of two TM image bands: (a) between bands TM 3 and TM 4, and (b) between bands TM 4 and TM 5 . 


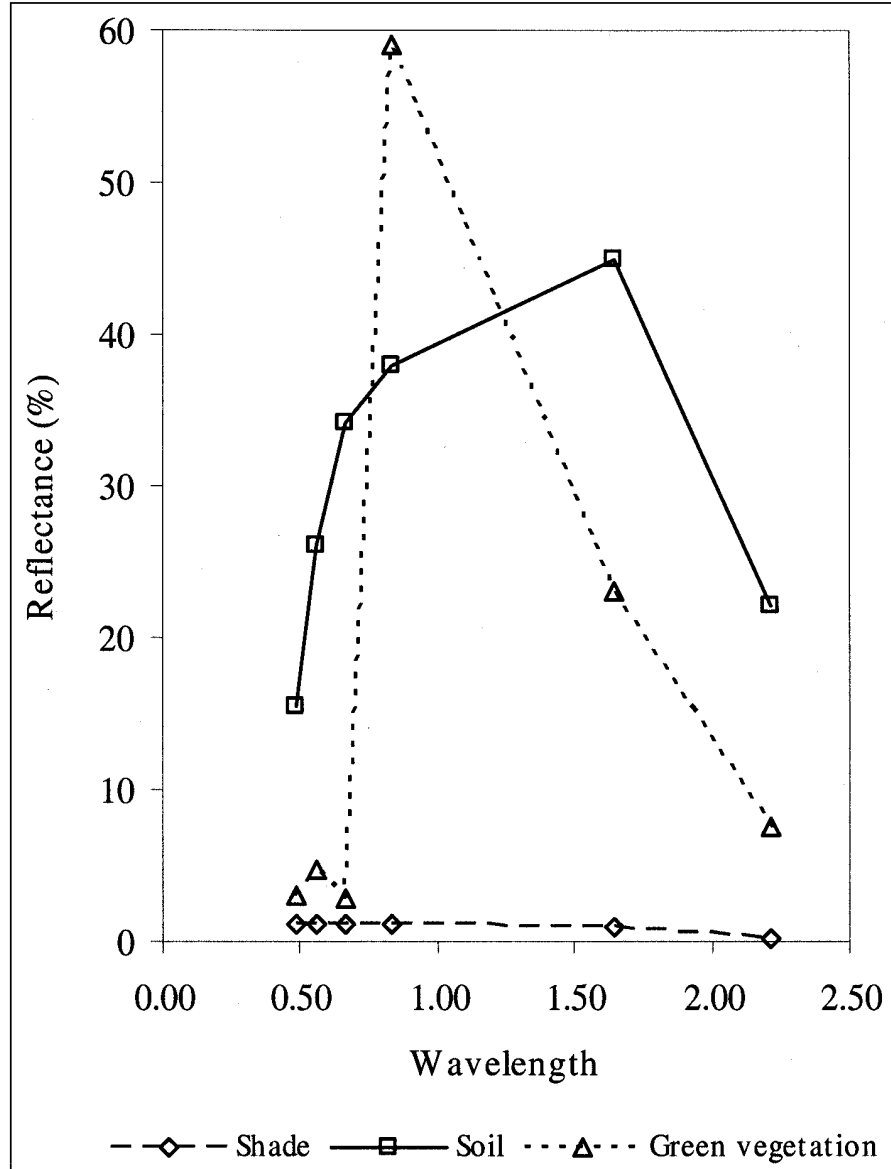

Figure 3. Reflectance characteristics of three selected image endmembers.

from the two tails of the histogram based on trial-and-error procedure. In this study, the selection of thresholds was based on the mean and standard deviation of unchanged land-cover classes, because unchanged land covers have normally distributed histograms (the mean value is close to zero) but changed land covers do not. The threshold values of unchanged land covers were identified on the fraction images through statistical analysis of 25 unchanged land-cover sample plots. Different standard deviations (from 2.5 to 3.5) were tested to find a suitable threshold for change detection. Thus, three binary change/non-change detection images were developed from the three fraction differencing images. The final change/non-change detection image was developed through the "or" overlay operation. This means that any change identified from each fraction differencing image was assigned as change in the final detection image.

Visual interpretation of multitemporal color composite is an alternative way to analyze land-cover change because it can make full use of the analyst's knowledge. When $\Delta$ Shade, $\Delta \mathrm{GV}$, and $\Delta$ Soil are assigned as red, green, and blue, respectively, the color composite image can tell us how the different land-cover types have changed. For example, red in the color composite indicates a high shade differencing value associated with both low GV and soil fraction differencing values, implying the change from mature forest to successional vegetation because $\mathrm{GV}$ and soil fractions are similar between mature forest and sucessional vegetation, but the shade fraction is decreased from mature forest to successional vegetation owing to their different forest stand structures, i.e., high shade fraction values for mature forest but low shade values for successional vegetation. Yellow in the color composite indicates high values in the shade and GV fraction differencing images associated with low or negative values in the soil fraction differencing image, implying the change from mature forest to bare land or pasture (in the dry season, some pastures are dead). The conversion from mature forest to bare land or pasture makes significant change in forest stand structure, leading to decreasing shade and GV fractions from mature forest to bare land or pasture, but increasing soil fraction values. Other colors can also be used to analyze the land-cover change trajectories because the fractions represent physical characteristics.

Overall change/non-change information is not sufficient for many research topics and applications. Hence, a detailed landcover "from-to" change detection is often required. In this study, five land-cover types were identified: mature forest (MF); secondary succession (SS), composed of initial (SS1) and advanced (SS2) succession; agricultural land and pasture (AP); bare land including urban areas and bare soils (UB); and water (WA). Thus, five land-cover types can produce 25 possible change trajectories. Figure 4 illustrates the trajectories of land-cover change in the Rondônia region of Brazil (Batistella, 2001). It indicates that mature forest could be converted to different land-cover types such as pastures, successional vegetation, agricultural lands, and roads after deforestation. Pasture can be transformed to successional vegetation, agricultural lands, bare lands, and so on. In practice, some change trajectories are unreasonable or impractical. For example, the change trajectories from agropastoral lands or young successional vegetations to mature forest in a 4-year period (from 1994 to 1998 in this study) are improbable. Also, some changes are caused by image registration errors and spatial resolution limitation. For example, the changes in water areas in this study are caused by the TM medium-spatial resolution $(30 \mathrm{~m})$ and multitemporal image registration errors because the river width is often less than $30 \mathrm{~m}$ (one pixel) and the registration errors may reach over $15 \mathrm{~m}$. After a careful analysis of all possible changes, six change trajectories and five unchanged classes were defined (Table 1).

The "from-to" change detection was produced using a postclassification comparison method. Thus, the critical step is to develop an accurate land-cover classification image of each date separately. In this study, data from a total of 134 plots covering the five classes were collected in 1999. Each plot was linked to the 1998 fraction images. A window size of $3 \times 3$ was used to extract the fraction value for each plot. The mean, standard deviation, minimum and maximum values were calculated to define the thresholds for each land-cover class. A detailed description of threshold definition is provided in Lu et al. (2003b). After definition of the threshold for each landcover type, a decision tree classifier was used to conduct the 


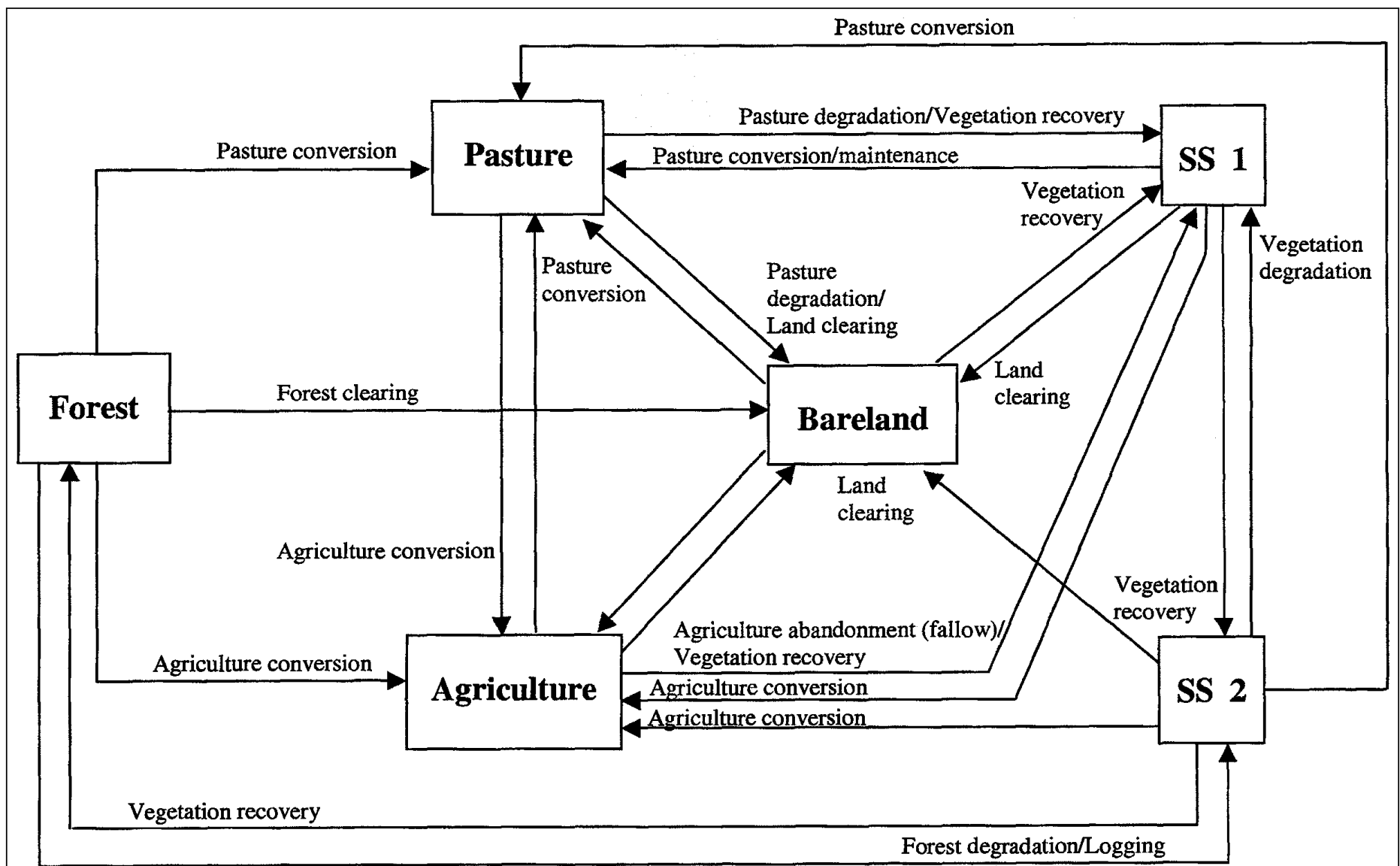

Figure 4. Trajectories of land-cover change in Rondônia.

Table 1. Definition of land-cover change trajectories used in this study.

\begin{tabular}{lll}
\hline Type & Change trajectories & Meaning \\
\hline Changed & MF to SS & Mature forest in 1994 was changed to SS in 1998 \\
& MF to AP or UB & Mature forest in 1994 was changed to agropastoral land, built-up land, or bare land in 1998 \\
& SS to AP or UB & SS in 1994 was changed to agropastoral land, built-up land, or bare land in 1998 \\
& AP or UB to SS & Agropastoral land or bare land in 1994 was changed to SS in 1998 \\
& AP to UB & Agropastoral land in 1994 was changed to built-up or bare land in 1998 \\
& UB to AP & Bare land in 1994 was changed to agropastoral land in 1998 \\
Unchanged & MF, SS, AP, UB, and WA & Unchanged land-cover types between both dates \\
\hline
\end{tabular}

Note: MF, mature forest; SS, secondary succession; UB, urban areas and bare lands; AP, agropastoral lands; WA, water.

land-cover classification based on the fraction images ( $\mathrm{Lu}$ et al., 2003b). The same thresholds were also used for the 1994 fraction images to produce the land-cover classification image.

\section{Results}

\section{Land-cover change/non-change detection}

Visual analysis of fraction images is useful for understanding the characteristics of different land-cover types. Figure $\mathbf{5}$ provides comparisons of the multitemporal fraction images derived from 1994 and 1998 TM images. In the shade fraction image, water appears white and mature forests appear bright grey owing to their high shade fraction values. Successional vegetation, some agricultural land such as coffee plantations and degraded pastures appear grey. Urban areas, roads, and bare soils appear dark grey. On the GV fraction image, successional vegetation appears white owing to its high GV fraction values. Mature forests appear bright grey. Pastures and agricultural lands had a wide variation of GV fraction values owing to their different vegetation cover densities. Some of them (e.g., degraded pastures, coffee plantations) had similar $\mathrm{GV}$ fractions as successional vegetation. The very low GV fraction values of water, urban areas, and bare soils make them appear black on the GV fraction image. In contrast, urban areas, roads, and bare soils appear white on the soil fraction because of their high fraction values. Pastures and agricultural lands appear grey, successional and mature forests and water areas 

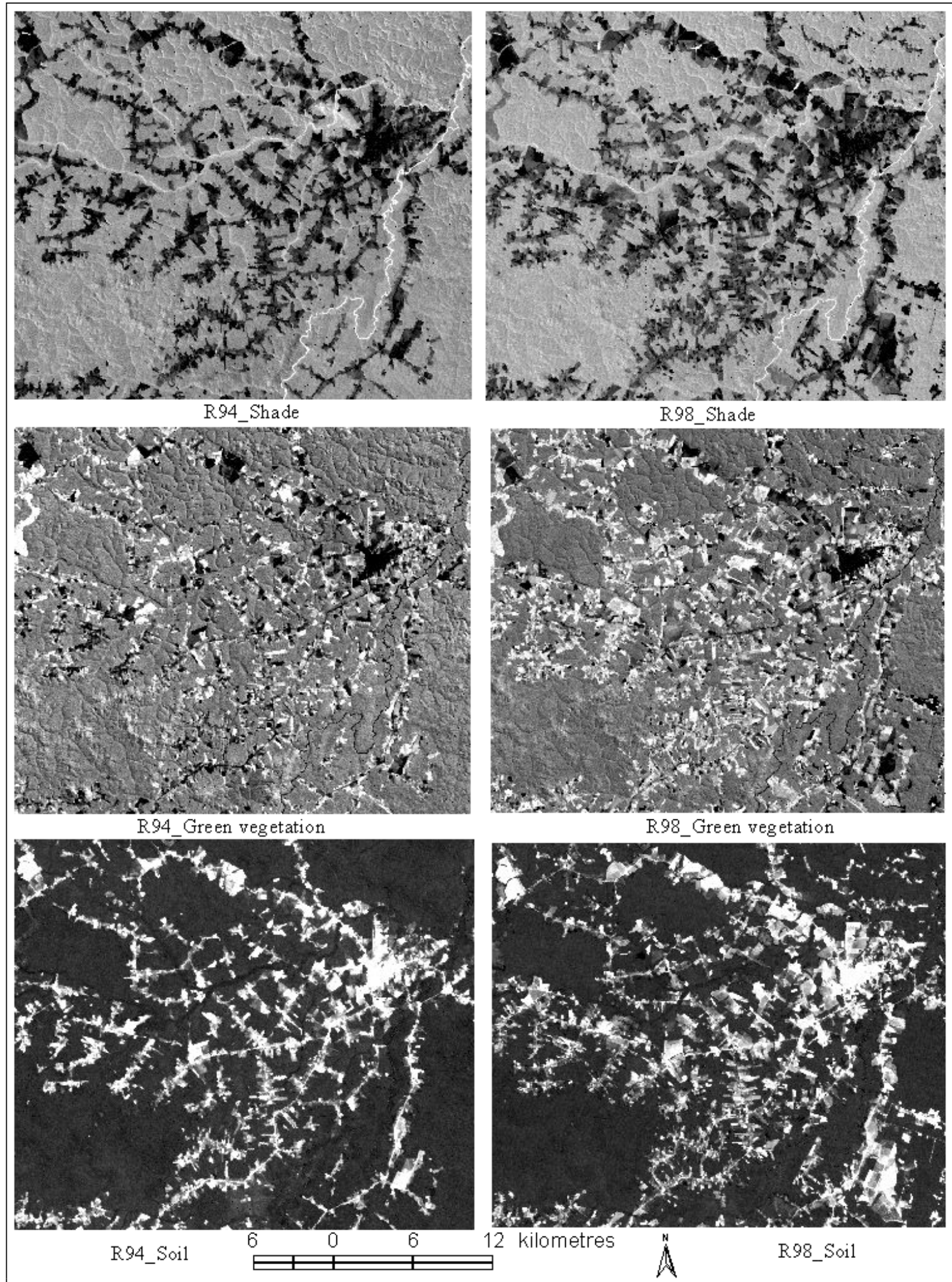

Figure 5. Characteristics of fraction images in Rondônia.

appear black owing to their very low soil fraction values. The different characteristics of land-cover types on the fraction images provide the basis for understanding the classification of land-cover classes. Comparisons of the same fraction images between 1994 and 1998 indicate that the unchanged land covers have similar grey tones. For example, unchanged mature 
forests have similar bright grey tones in the shade and GV fraction images because of their high shade and GV fraction values and have dark grey tones in the soil fraction images owing to their very low soil fraction values. However, for those changed land covers, the characteristics between both dates of fraction images vary depending on the change trajectory. Thus, differencing images between the same fractions of both dates provides new insights to visually interpret the land-cover change.

Figure 6 illustrates the fraction differencing images and the land-cover change/non-change detection image. The grey in this figure indicates the unchanged land-covers. The white in the shade differencing image indicates the significant decrease of shade fraction values from 1994 to 1998, implying the change from mature forests to pastures or bare lands. The dark grey or black indicates a significant increase of shade values from 1994 to 1998, implying the change from initial to advanced successional stages. The white in the GV differencing image indicates high decrease in $\mathrm{GV}$ fraction values from 1994 to 1998, implying the change from successional vegetation to bare lands or pastures. The dark grey or black indicates high increase in GV values from 1994 to 1998, implying the change from bare lands or pastures to successional vegetation. The white in the soil fraction differencing image indicates the high decrease of soil fraction values from 1994 to 1998, implying the change from bare lands or pastures to successional vegetation, while the black indicates high increase of soil fractions, implying the change from

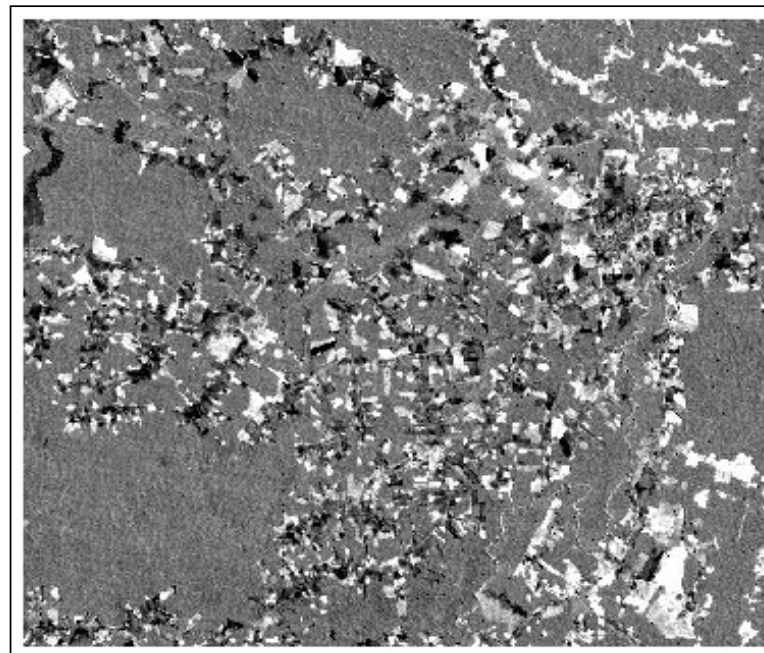

Shade fraction differencing image

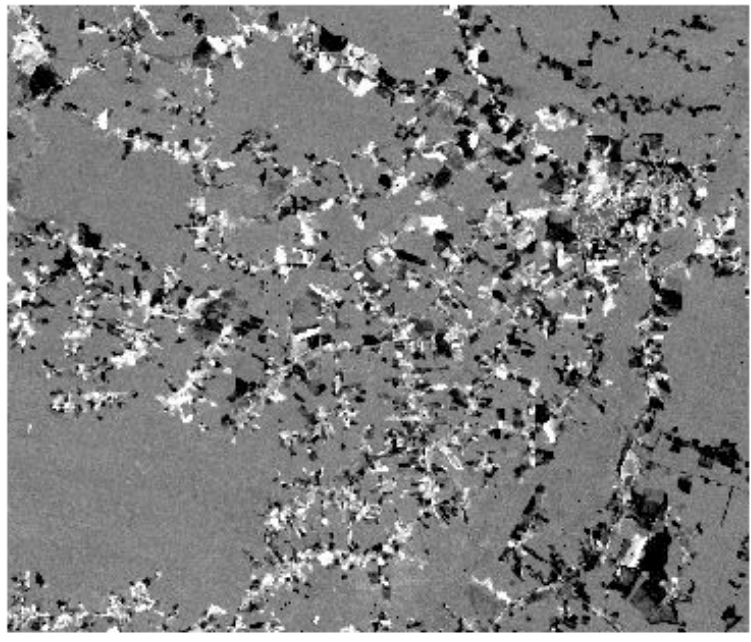

Soil fraction differencing image

4

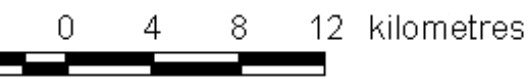

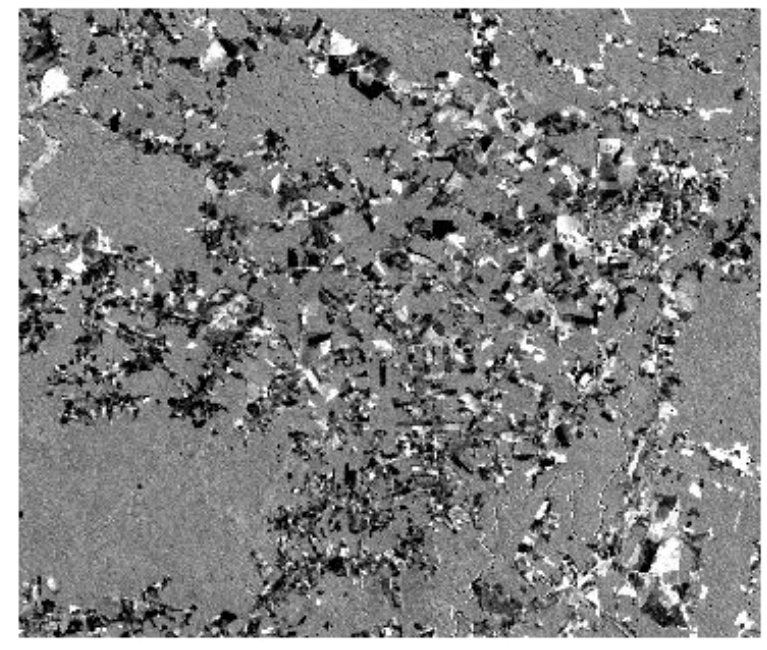

Green vegetation fraction differencing image

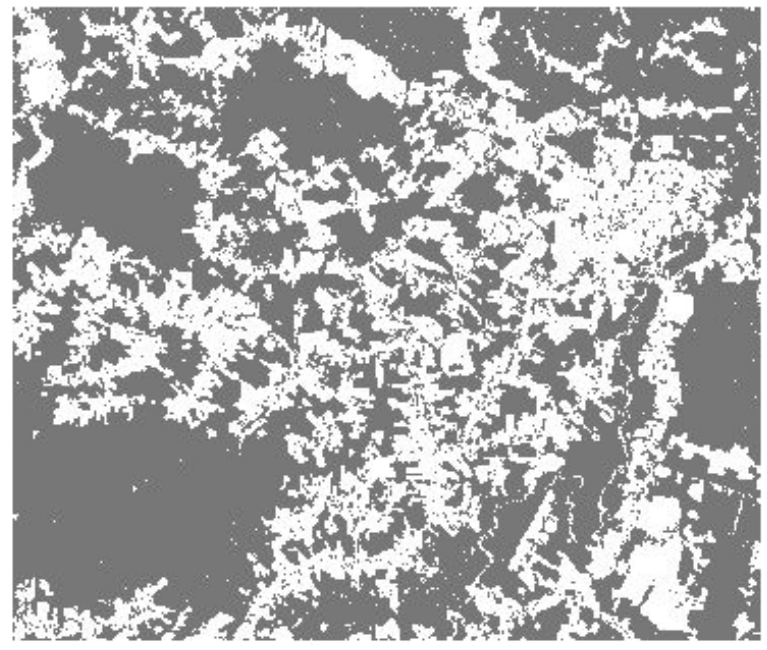

Land cover change/non-change detection

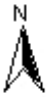

Figure 6. Characteristics of land-cover changes on the fraction differencing images in Rondônia. 
mature forests or successional vegetation to bare lands or pastures. The change/non-change detection result does include some errors caused by errors inherent in the image registration (e.g., river width) and the LSMA approach limitation (e.g., urban areas). Visual comparison of the change/non-change detection results with the multiple dates of TM image color composites indicated that almost all land-cover changes were accurately detected but for the urban areas and rivers. The possible reason of poor urban change detection is the complex fraction composition within the pixel in the urban landscape. Almost all pixels in the urban areas are mixed with different land-cover types owing to the limitation of spatial resolution of TM data and the fraction composition of each pixel is possibly different from that of its neighbor pixels. Thus, the image registration error may cause the difference on the fraction differencing image. This evidence is clearer in the single fraction differencing images. For example, in the GV fraction differencing image, the urban areas appear as grey (unchanged) because urban areas have very low GV fraction values. However, in the shade or soil fraction differencing image, many pixels in the urban areas appear bright grey owing to the impacts of variation of shade and soil fractions between fraction images of both dates.

A color composite of fraction differencing images can provide different insights about land-cover change detection information. Figure 7 illustrates a comparison of color composites between 1994 and 1998 TM images (bands TM 4, 5 , and 3 were assigned as red, green, and blue, respectively) and the fraction differencing image color composite ( $\Delta$ Shade, $\Delta \mathrm{GV}$, and $\Delta$ Soil were assigned as red, green, and blue, respectively). Visual interpretation and comparison of these color composites indicate that the different colors represent different land-cover change trajectories. For example, the land-cover class in the selected polygon in the 1994 TM color composite is a mature forest. In 1998, some mature forest was converted to agropastoral lands (some pastures have color similar to agricultural lands because of the dry season) and successional vegetation. The yellow color within the same polygon indicates the change from mature forest to agropastoral lands, and the red implies the change from mature forest to successional vegetation or agropastoral lands (such as coffee plantations). Thus, from the fraction differencing image color composite, land-cover change can be visually identified. Table 2 provides the major land-cover change trajectories associated with the colors in Figure 7. This analysis of fraction differencing image color composites is useful for further quantitative land-cover change detection using the multitemporal fraction images.

\section{Land-cover "from-to" change detection}

Figure 8 illustrates a comparison of fraction values among selected land-cover classes. It was developed from fraction images using the LSMA approach for the 1998 TM image, based on 134 sample sites covering different land-cover types. It indicates that mature forests and successional vegetation have very low soil fraction values while mature forests have higher shade fraction but lower GV fraction than successional vegetation. Agropastoral lands have relatively higher soil fraction but lower shade fraction than successional and mature forests. Urban areas and bare lands have the highest soil fraction values but much lower shade and GV values than vegetated areas. In contrast, water has the highest shade values but low soil and GV values. The different fraction compositions among the land-cover types provide the potential to accurately classify the land-cover types and implement change detection between two dates of fraction images. Therefore, the thresholds to distinguish land-cover types can be defined based on the typical land-cover classes from the sample plot data. These thresholds were then used to classify the entire study area for 1998 fraction images. Because stable and reliable fraction images also were developed from the 1994 TM image, the same thresholds were directly used for the 1994 fraction image for land-cover classification. Finally, the classified images of both dates were used to implement land-cover change detection using the post-classification comparison method, pixel by pixel.

Figure 9, which illustrates the land-cover change distribution between 1994 and 1998, was developed from bitemporal fraction images. It indicates that unchanged agropastoral lands are mainly distributed near the urban areas and along both sides of roads. Deforestation occurred along the roads and unchanged mature forest was located away from the roads and at large patches of forest reserves. The most obvious land-cover change is the conversion of mature forest to agropastoral lands or bare lands. Table 3 provides the statistical results of land-cover change detection between 1994 and 1998. The changes are mainly from the mature forest deforestation and vegetation regrowth, accounting for $56.93 \%$ (including $14.63 \%$ of the changes from mature forest to successional vegetation and $42.3 \%$ of the changes from mature forest to agropastoral lands and bare lands) and $25.8 \%$ of the total changed areas, respectively. In the unchanged areas, mature forest and agropastoral lands account for $73.7 \%$ and $21.6 \%$, respectively. The change detection accuracy assessment was not available for this study owing to the lack of ground-truth data for the 1994 TM data and the difficulty for visually interpreting between the successional vegetation, degraded pastures, and agroforestry based on TM images.

\section{Discussion}

The land-cover classification of historical remote sensing images using traditional classifiers is often problematic owing to the lack of training sample data. The LSMA approach avoids this dilemma because it provides accurate and stable fractions for multitemporal TM images. This allows the direct transfer of thresholds for each land-cover type developed on one date of fraction images to another date of fraction images. Cautions need to be taken when implementing the model transfer among multitemporal fraction images to make sure the fraction images were developed with high quality. The examination of fraction values for those unchanged objects is useful to assure that the 


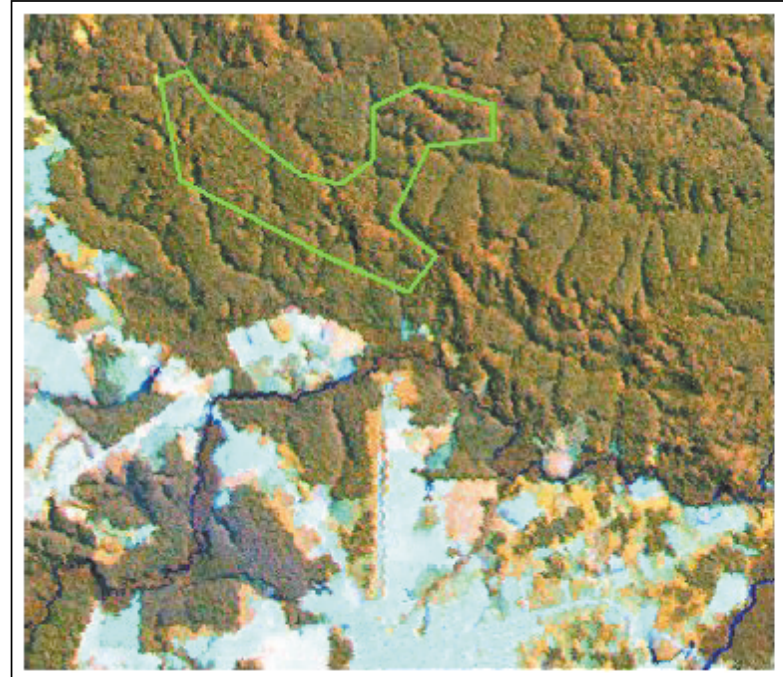

1994 TM image

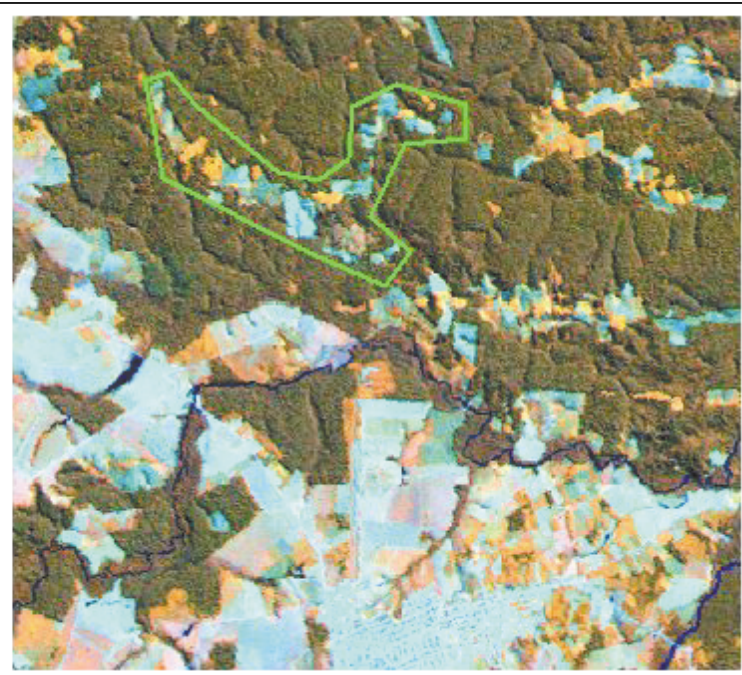

$1998 \mathrm{TM}$ image

TM image color composites (B and TM 4, 5,3/R, G, B)

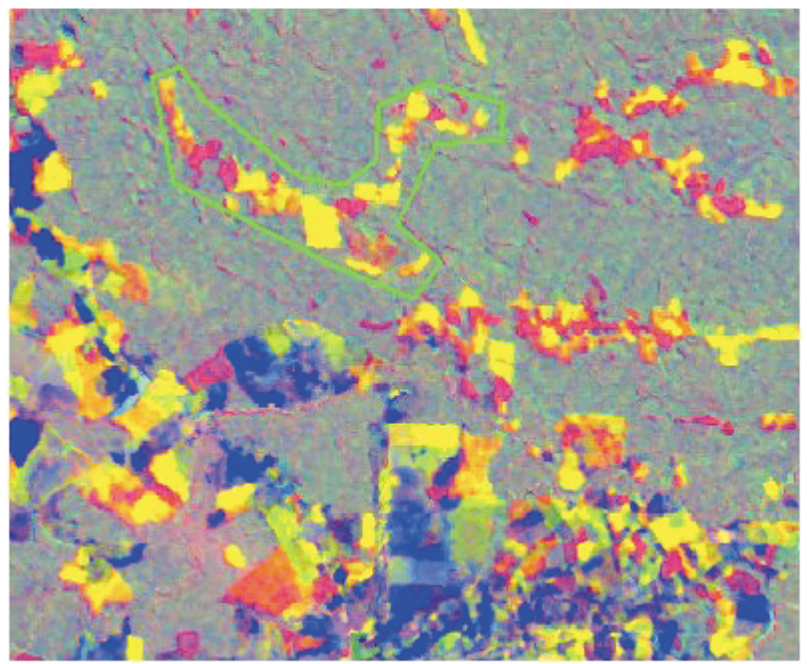

1994-1998 color composite using fraction differencing images

(Differencing images shade, green vegetation, and soil fractionas, respectively, as R, G. B)

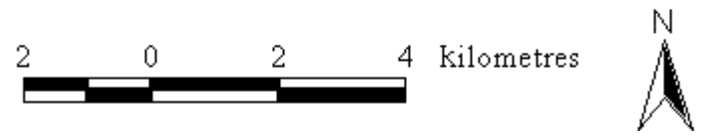

Figure 7. Comparison of land-cover change on the color composites between 1994 and 1998 TM images for the study area of Rondônia.

fraction values of the same unchanged objects have similar values on both dates of fraction images. If the fraction values are significantly different, checking the endmembers and the fraction images is necessary to verify that the endmembers selected are suitable. In the LSMA approach, endmember selection is a crucial step. The selection of suitable endmembers often involves an iterative process, i.e., selecting initial endmembers, refining these endmembers, evaluating fraction images, and then further refining endmembers. Finally, selected endmembers should be independent of each other. For a study area with complex landscape structures, such as those urban areas composed of residential, commercial and industrial uses, agricultural lands, and forests, identification and selection of proper endmembers for the whole study area is often not straightforward. Two possible approaches may be taken for 
Table 2. Interpretation of some typical land-cover change trajectories in the color composite with bi-temporal fraction differencing images.

\begin{tabular}{lllll}
\hline $\begin{array}{l}\text { Major change } \\
\text { trajectories }\end{array}$ & $\begin{array}{l}\text { Shade change } \\
(1994-1998)\end{array}$ & $\begin{array}{l}\text { GV change } \\
(1994-1998)\end{array}$ & $\begin{array}{l}\text { Soil change } \\
(1994-1998)\end{array}$ & Color composite $^{a}$ \\
\hline MF to SS & ++ & 0 or - & 0 & Red \\
MF to AP or UB & ++ & ++ & -- & Yellow \\
SS to AP or UB & 0 or + & ++ & -- & Between green and yellow \\
AP or UB to SS & 0 or - & -- & ++ & Blue \\
AP to UB & 0 & + & - & Between green and yellow, but dark \\
UB to AP & 0 & - & + & Dark blue \\
\hline
\end{tabular}

Note: MF, mature forest; SS, secondary succession; UB, urban areas and bare lands; AP, agropastoral lands; ++, higher change amounts (decreased from 1994 to 1998) than +; --, higher change amounts (increased from 1994 to 1998) than -; 0, almost unchanged between 1994 and 1998.

${ }^{a}$ Shade, GV, soil differencing images as red, green, and blue, respectively.

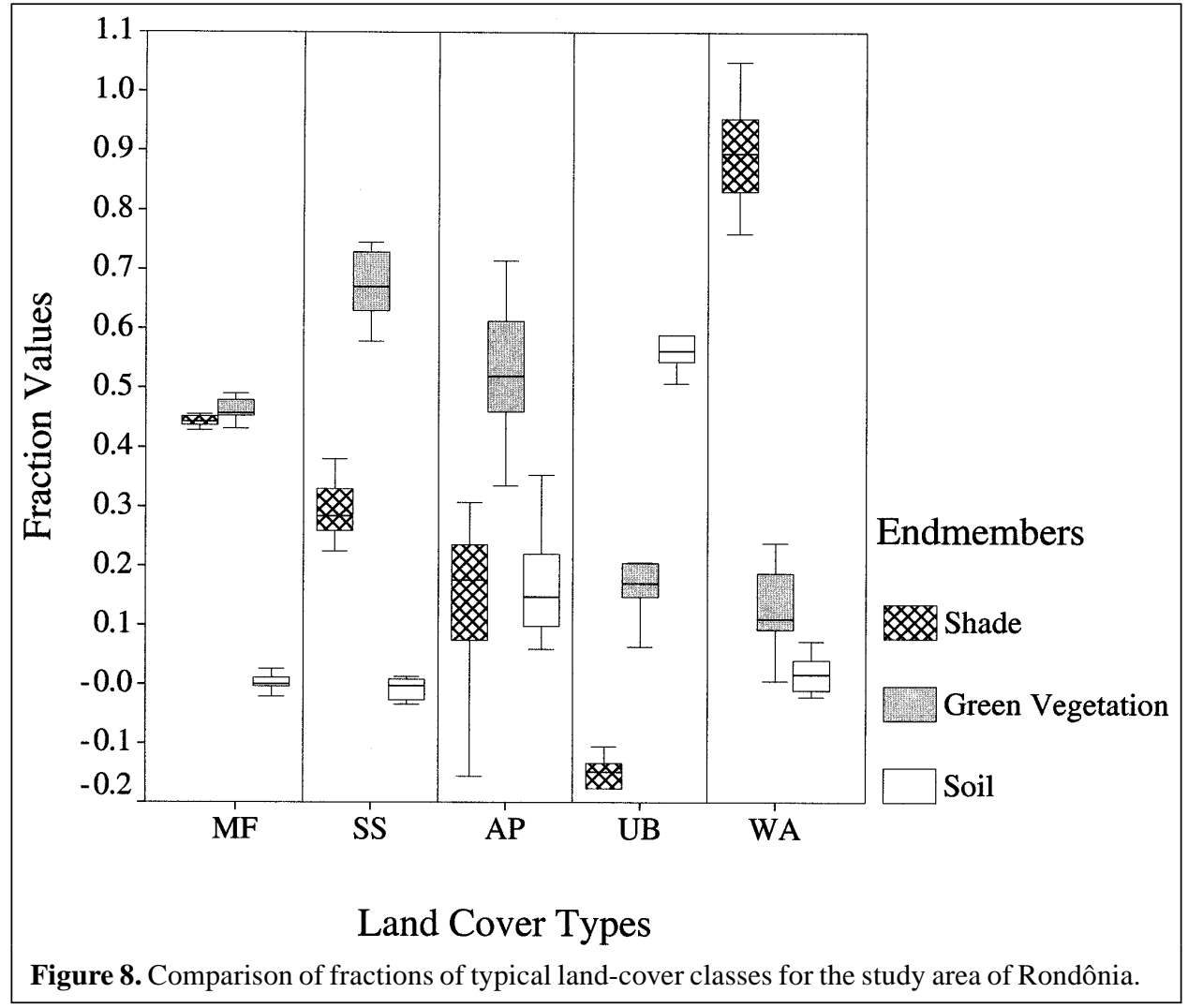

effective derivation of endmembers in an intricate urban area: (1) stratification or (2) use of multiple endmembers.

Stratification of the whole study area into smaller regions of similar landscape structures may be necessary to facilitate the derivation of high quality fraction images. For example, in a study area dominated by residential, commercial, and industrial uses, possible endmembers may be GV, shade, and impervious surface, while in an agriculture-dominated region, endmembers may be GV, shade, and soil. In the forested area, GV, shade, and non-photosynthetic vegetation (NPV) may be the most appropriate choice of endmembers. However, if GV, shade, impervious surface, soil, and NPV are used for the entire study area without stratification, the process for developing high quality fraction images could be lengthy and technically difficult because of potentially high correlations between some endmembers, e.g., between impervious surfaces, soil, and NPV (Lu and Weng, 2004). On the other hand, a limited number of endmembers may not account for the spectral variability of the complex landscape and cannot tackle the mixed pixel problem. In urban regions, because of the complexity of impervious surfaces, identification of suitable impervious surfaces as endmembers, based on remote-sensing features, is often difficult and the impervious surfaces tend to be confused with soils. Hence, a possible method is to use multiple endmember models (Roberts et al., 1998b). The multiple-endmember LSMA approach permits a large number of endmembers to be modeled across a scene and has shown a better performance than the standard LSMA approach (Roberts et al., 1998b). The 


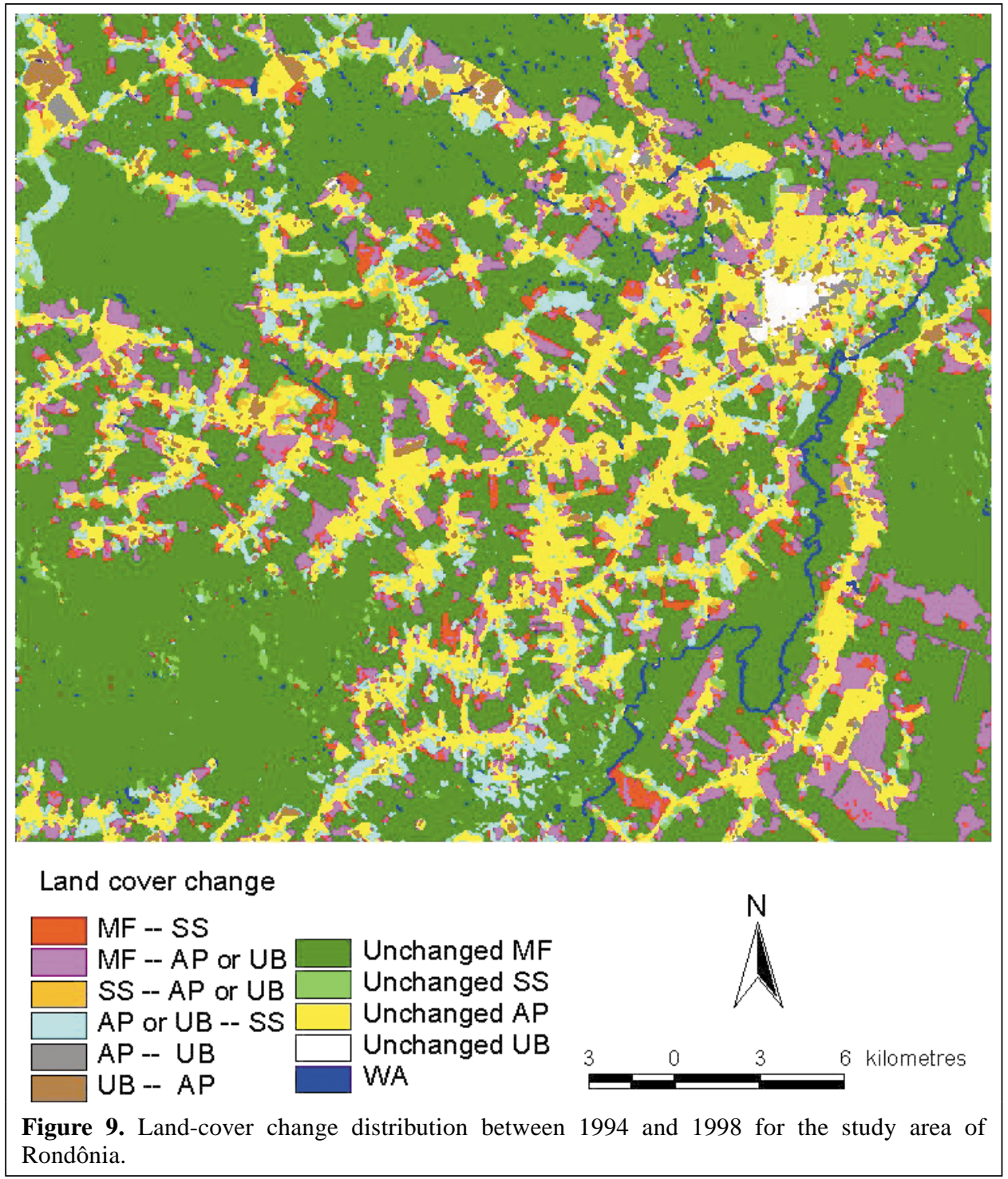

Table 3. Statistical results of land-cover change detection between 1994 and 1998.

\begin{tabular}{lrrlrr}
\hline Change trajectory & Area $(\mathrm{ha})$ & Area $(\%)$ & Unchanged & Area (ha) & Area $(\%)$ \\
\hline MF to SS & 3340.53 & 14.63 & MF & 56416.50 & 73.71 \\
MF to UB or AP & 9658.44 & 42.30 & SS & 1958.76 & 2.56 \\
SS to UB or AP & 1225.80 & 5.37 & AP & 16520.40 & 21.59 \\
UB or AP to SS & 5891.85 & 25.80 & UB & 502.47 & 0.66 \\
AP to UB & 852.57 & 3.73 & WA & 1136.07 & 1.48 \\
UB to AP & 1864.17 & 8.16 & & & \\
Total area & 22833.36 & & Total area & 76534.20 & \\
\hline
\end{tabular}

Note: MF, mature forest; SS, secondary succession; UB, urban areas and bare lands; AP, agropastoral lands; WA, water.

multiple-endmember LSMA approach may be more suitable for use in urban landscapes. For this study, three endmembers were suitable for unmixing the non-urban areas for land-cover change detection because very few urban areas exist in this study area.

The fraction differencing images have their own characteristics and merits in land-cover change detection. For example, the soil fraction differencing image reflects more effectively the vegetation and nonvegetation change, but is not sensitive to changes within vegetation types. In contrast, the shade and $\mathrm{GV}$ fraction differencing images are more effective for vegetation change detection. Therefore, the selection of appropriate endmember fraction differencing images provides the flexibility to implement change detection according to specific research needs. 


\section{Conclusions}

Using traditional methods, land-cover change detection in moist tropical regions is often difficult. The LSMA has proved to be a powerful tool that decomposes the image data into fraction images with physical meanings and has shown the capability to implement land-cover classification and change detection. This study indicates that fraction differencing images have different characteristics in land-cover change detection. Shade or GV fraction differencing images are more suitable to detect vegetation change, while the soil fraction differencing image is more suitable to detect vegetation/ nonvegetation change. The LSMA is especially suitable to detect detailed "from-to" change. The stable and reliable fraction images developed using LSMA from multitemporal images provide the capability to directly transfer the thresholds of each land-cover type from one date of fraction images to other dates of fraction images. This characteristic is particularly valuable to classify land-cover types for historical remotely sensed data to implement accurate land-cover change detection.

\section{Acknowledgments}

The authors wish to thank the National Science Foundation (grants 95-21918 and 99-06826), the National Aeronautics and Space Administration (grant N005-334), and Brazil's Program for the Advancement of Education (CAPES) for their support of the research that resulted in this paper. This study is a part of the Large-Scale Biosphere-Atmosphere Experiment in Amazônia (LBA) program, LC-09, which is examining the human and physical dimensions of land-use and land-cover change. We also thank collaborators in Brazil, especially the LBA program, Embrapa Satellite Monitoring, INPE, and the population of the study area, who made this work possible.

\section{References}

Adams, J.B., Smith, M.O., and Gillespie, A.R. 1993. Imaging spectroscopy: interpretation based on spectral mixture analysis. In Remote Geochemical Analysis, Topics in Remote Sensing 4. Edited by C.M. Pieters and P.A.J. Englert. Cambridge University Press, Cambridge, U.K. pp. 145-166.

Adams, J.B., Sabol, D.E., Kapos, V., Filho, R.A., Roberts, D.A., Smith, M.O., and Gillespie, A.R. 1995. Classification of multispectral images based on fractions of endmembers: application to land-cover change in the Brazilian Amazon. Remote Sensing of Environment, Vol. 52, pp. 137-154.

Aguiar, A.P.D., Shimabukuro, Y.E., and Mascarenhas, N.D.A. 1999. Use of synthetic bands derived from mixing models in the multispectral classification of remote sensing images. International Journal of Remote Sensing, Vol. 20, pp. 647-657.

Bateson, A., and Curtiss, B. 1996. A method for manual endmember selection and spectral unmixing. Remote Sensing of Environment, Vol. 55, pp. 229243.

Batistella, M. 2001. Landscape change and land-use/land-cover dynamics in Rondônia, Brazilian Amazon. CIPEC Dissertation Series, No. 7. Center for the Study of Institutions, Population, and Environmental Change (CIPEC), Indiana University, Bloomington, Ind.

Bognola, I.A., and Soares, A.F. 1999. Solos das "glebas 01, 02, 03 e 06" do Município de Machadinho d'Oeste, RO. Embrapa Monitoramento por Satélite, Campinas, Brazil. Pesquisa em Andamento, n. 10.

Brondízio, E.S., Moran, E.F., Mausel, P., and Wu, Y. 1994. Land use change in the Amazon estuary: patterns of Caboclo settlement and landscape management. Human Ecology, Vol. 22, pp. 249-278.

Brondízio, E.S., Moran, E.F., Mausel, P., and Wu, Y. 1996. Land-cover in the Amazon estuary: linking of the Thematic Mapper with botanical and historical data. Photogrammetric Engineering \& Remote Sensing, Vol. 62, pp. 921-929.

Center for the Study of Institutions, Population, and Environmental Change (CIPEC). 1998. International Forestry Resources and Institutions (IFRI) research program, field manual. CIPEC, Indiana University, Bloomington, Ind.

Chavez, P.S., Jr. 1996. Image-based atmospheric corrections — revisited and improved. Photogrammetric Engineering \& Remote Sensing, Vol. 62, pp. $1025-1036$.

Cochrane, M.A., and Souza, C.M., Jr. 1998. Linear mixture model classification of burned forests in the eastern Amazon. International Journal of Remote Sensing, Vol. 19, pp. 3433-3440.

Coppin, P.R., and Bauer, M.E. 1996. Digital change detection in forest ecosystems with remote sensing imagery. Remote Sensing Reviews, Vol. 13, pp. 207-234.

DeFries, R.S., Hansen, M.C., and Townshend, J.R.G. 2000. Global continuous fields of vegetation characteristics: a linear mixture model applied to multiyear $8 \mathrm{~km}$ AVHRR data. International Journal of Remote Sensing, Vol. 21, pp. 1389-1414.

Elmore, A.J., Mustard, J.F., Manning, S.J., and Lobell, D.B. 2000, Quantifying vegetation change in semiarid environments: precision and accuracy of spectral mixture analysis and the normalized difference vegetation index. Remote Sensing of Environment, Vol. 73, pp. 87-102.

Instituto Nacional de Pesquisas Espaciais (INPE). 2002. Monitoring of the Brazilian Amazon Forest by Satellite 2000-2001. INPE, Brazil.

Jensen, J.R. 1996. Introductory digital image processing: a remote sensing perspective. 2nd ed. Prentice Hall, Upper Saddle River, N.J.

Lu, D., and Weng, Q. 2004. Spectral mixture analysis of the urban landscapes in Indianapolis with Landsat ETM+ imagery. Photogrammetric Engineering \& Remote Sensing. In press.

Lu, D., Mausel, P., Brondizio, E., and Moran, E. 2002. Assessment of atmospheric correction methods for Landsat TM data applicable to Amazon basin LBA research. International Journal of Remote Sensing, Vol. 23, pp. 2651-2671.

Lu, D., Batistella, M., and Moran, E. 2003a. Integration of vegetation inventory data and Thematic Mapper image for Amazonian successional and mature forest classification. In Proceedings of the ASPRS 2003 Annual Conference, 5-9 May 2003, Anchorage, Alaska. [CD-ROM]. American Society of Photogrammetry and Remote Sensing, Bethesda, Md.

Lu, D., Moran, E., and Batistella, M. 2003b. Linear mixture model applied to Amazônian vegetation classification. Remote Sensing of Environment, Vol. 87, No. 4, pp. 456-469.

Lu, D., Mausel, P., Brondizio, E., and Moran, E. 2004. Change detection techniques. International Journal of Remote Sensing. In press. 
Mausel, P., Wu, Y., Li, Y., Moran, E.F., and Brondízio, E.S. 1993. Spectral identification of succession stages following deforestation in the Amazon. Geocarto International, Vol. 8, pp. 61-72.

Moran, E.F. 1981. Developing the Amazon. Indiana University Press, Bloomington, Ind.

Moran, E.F., Brondízio, E.S., and Mausel, P. 1994a. Secondary succession. Research and Exploration, Vol. 10, pp. 458-476.

Moran, E.F., Brondízio, E.S., Mausel, P., and Wu, Y. 1994b. Integrating Amazonian vegetation, land use and satellite data. BioScience, Vol. 44, pp. 329-338.

Mustard, J.F., and Sunshine, J.M. 1999. Spectral analysis for earth science: investigations using remote sensing data. In Remote Sensing for the Earth Sciences: Manual of Remote Sensing. Edited by A.N. Rencz. John Wiley \& Sons, New York. Vol. 3, pp. 251-307.

Roberts, D.A., Batista, G.T., Pereira, J.L.G., Waller, E.K., and Nelson, B.W. 1998a. Change identification using multitemporal spectral mixture analysis: applications in eastern Amazônia. In Remote Sensing Change Detection: Environmental Monitoring Methods and Applications. Edited by R.S. Lunetta and C.D. Elvidge, Ann Arbor Press, Ann Arbor, Mich. pp. $137-161$.

Roberts, D.A., Gardner, M., Church, R., Ustin, S., Scheer, G., and Green, R.O. 1998b. Mapping chaparral in the Santa Monica mountains using multiple endmember spectral mixture models. Remote Sensing of Environment, Vol. 65, pp. 267-279.

Roberts, D.A., Numata, I., Holmes, K.W., Batista, G., Krug, T., Monteiro, A., Powell, B., and Chadwick, O. 2002. Large area mapping of land-cover change in Rondônia using multitemporal spectral mixture analysis and decision tree classifiers. Journal of Geophysical Research, Vol. 107(D20), 8073 (LBA 40-1 - 40-18).

Rogan, J., Franklin, J., and Roberts, D.A. 2002. A comparison of methods for monitoring multitemporal vegetation change using Thematic Mapper imagery. Remote Sensing of Environment, Vol. 80, pp. 143-156.

Rondônia. 1998. Diagnóstico sócio-econômico do Estado de Rondônia e assistência técnica para formulação da segunda aproximação do zoneamento sócio-econômico-ecológico - Climatologia, v. 1. Governo de Rondônia - PLANAFLORO, Porto Velho, Brazil.

Schmink, M., and Wood, C.H. 1992. Contested frontiers in Amazônia. Columbia University Press, New York.

Serpico, S.B., and Bruzzone, L. 1999. Change detection. In Information processing for remote sensing. Edited by C.H. Chen. World Scientific Publishing Co., Singapore. pp. 319-336.

Settle, J.J., and Drake, N.A. 1993. Linear mixing and the estimation of ground cover proportions. International Journal of Remote Sensing, Vol. 14, pp. 1159-1177.

Shimabukuro, Y.E., Batista, G.T., Melio, E.M.K., Moreira, J.C., and Duarte, V. 1998. Using shade fraction image segmentation to evaluate deforestation in Landsat Thematic Mapper images of the Amazon region. International Journal of Remote Sensing, Vol. 19, pp. 535-541.

Singh, A. 1989. Digital change detection techniques using remotely sensed data. International Journal of Remote Sensing, Vol. 10, pp. 989-1003.

Smith, M.O., Ustin, S.L., Adams, J.B., and Gillespie, A.R. 1990. Vegetation in Deserts: I. A regional measure of abundance from multispectral images. Remote Sensing of Environment, Vol. 31, pp. 1-26.
Theseira, M.A., Thomas, G., and Sannier, C.A.D. 2002. An evaluation of spectral mixture modeling applied to a semi-arid environment. International Journal of Remote Sensing, Vol. 23, pp. 687-700.

Tompkins, S., Mustard, J.F., Pieters, C.M., and Forsyth, D.W. 1997. Optimization of endmembers for spectral mixture analysis. Remote Sensing of Environment, Vol. 59, pp. 472-489.

Ustin, S.L., Smith, M.O., Jacquemoud, S., Verstraete, and M., Govaerts, Y. 1999. Geobotany: vegetation mapping for earth sciences. In Remote sensing for the earth sciences: Manual of remote sensing. Edited by A.N. Rencz. John Wiley \& Sons. Vol. 3, pp. 189-233.

Yool, S.R., Makaio, M.J., and Watts, J.M. 1997. Techniques for computerassisted mapping of rangeland change. Journal of Range Management, Vol. 50, pp. 307-314.

Yuan, D., Elvidge, C.D., and Lunetta, R.S. 1998. Survey of multispectral methods for land-cover change analysis. In Remote sensing change detection: Environmental monitoring methods and applications. Edited by R.S. Lunetta and C.D. Elvidge. Ann Arbor Press, Chelsea, Mich. pp. 2139. 